\title{
FLOC SIZE VARIABILITY UNDER STRONG TURBULENCE: OBSERVATIONS AND ARTIFICIAL NEURAL NETWORK MODELING
}

\author{
Cihan Sahin*, H. Anil Ari Guner*, Mehmet Ozturk*, Alexandru Sheremet ${ }^{\dagger}$
}

\begin{abstract}
The flocculation of cohesive sediment in the presence of waves is investigated using high-resolution field observations and a newly-developed flocculation model based on artificial neural networks. Vertical profiles of suspended sediment concentration and turbulent intensity are estimated using measurements of current profile and acoustic backscatter. The vertical distribution of floc size is estimated using an artificial neural network (ANN) that is trained and validated using floc size measurements at one vertical level. Data analysis suggests a linear correlation between suspended sediment concentration and turbulence intensity. Observations and numerical simulations show that floc size is inversely related to sediment concentration, turbulence intensity and water temperature. The numerical results indicate that floc growth is supported by low concentration and low turbulence. In the vertical direction, mean size of flocs decreases toward the bottom, suggesting floc breakage due to increasing turbulence intensity toward the bed. A significant decrease in turbulent shear could occur within the bottom few-cm, related to increased damping of turbulence by sediment induced density stratification. The results of the numerical simulations presented here are consistent with the concept of a cohesive sediment particle undergoing aggregation-fragmentation processes, and suggest that the ANN can be a precise tool to study flocculation processes.
\end{abstract}

Key words: flocculation; cohesive sediment; artificial neural network; suspended sediment; turbulence; bottom boundary layer; Louisiana Shelf

*Department of Civil Engineering, Yildiz Technical University, Esenler, Istanbul 34210, Turkey; cisahin@inm.yildiz.edu.tr; +90-212-383-5175; Fax: +90-212-383-5133

${ }^{\dagger}$ Engineering School of Sustainable Infrastructure and Environment (ESSIE), University of Florida, 365 Weil Hall, Gainesville, FL 32611, USA 


\section{Introduction}

Sediment transport plays a critical role in the evolution of rivers, bays, and estuaries, as it impacts not only the morphology of these systems, but also aquatic habitats, water quality, and turbidity. Bottom sediments provide habitat for benthic organisms and are a source of nutrients as well as potentially toxic materials such as pesticides and metals that are readily transported with sediment particles (Hammond at al., 1985; Kuwabara et al., 1989). These particles are often transported as a suspension. For example, 87-99\% of sediment delivered to San Francisco Bay during the wet season, from late fall to early spring, arrives as suspended load (Buchanan and Schoellhamer, 1999). Suspended sediments also affect photosynthesis by decreasing light transmission, and the deposition of sediments in shipping channels requires periodic dredging to maintain those channels in navigable conditions (Buchanan and Schoellhamer, 1999).

Settling velocity of suspensions of non-cohesive primary particles can be described depending on the relative density, size and shape of the particles, using well-defined expressions (e.g., Stokes Law; Stokes, 1851) since the only forces involved in suspended particle motion are gravity and flow resistance (e.g., Soulsby, 1997). In bays and estuaries, however, suspended particles rarely exist in their primary state; instead, they are typically heterogeneous aggregates of mineral grains, biogenic debris, bacteria, and organic material (MacDonald et al., 2013; Thorne et al., 2014) called flocs which behave as an identifiable sedimentary unit (Mehta, 2013). Flocculation, i.e., the formation of flocs, has long been recognized as a dynamic process (e.g., Winterwerp and van Kesteren, 2004) driven by environmental conditions, primarily through flow-sediment interaction (e.g., Tsai et al., 1987; Burban, 1987; Burban et al., 1990; Manning, 2004). Aggregation of primary particles occurs when these particles collide, and a significant number of these collisions result in adhesion. Aggregation transitions to fragmentation if the intensity of collisions or turbulent shear exceeds a certain threshold. In this case, a limiting maximum size might occur (McCave, 1984). Particle concentration and turbulent shear, which affect the intensity and number of collisions, are known to be the dominant parameters controlling the size of the flocs (Berhane et al., 1997; Dyer and Manning, 1999; Uncles, 2010). Flocculation is expected to occur more rapidly when salinity increases since the flocs are more likely to come into close contact and adhere to one another in saline water (Krone, 1962). Increasing temperature was observed to cause floc size and settling velocity reduction, causing changes in viscosity inducing a weaker floc (Dearnaley, 1991; Lau, 1994; Fitzpatrick et al., 2004). Thus, flocs in suspension experience various processes such as aggregation, fragmentation, repacking, remineralization, deposition, and eventually 
subsequent resuspension. Because bi-modally distributed floc populations are common (Manning and Dyer, 2002), it has been suggested that a distinction should be made between micro- and macro-flocs (Eisma, 1986; Manning, 2001). Macro-flocs are large (diameter of $D>160 \mu \mathrm{m}$ ), highly porous (porosity larger than 90\%), fragile, fast settling aggregates. The smaller micro-flocs $(D<160 \mu \mathrm{m})$ are generally considered to be the building blocks from which the macro-flocs are composed. Micro-flocs are much more resistant to break-up by turbulent shear. Generally, micro-flocs tend to have slower settling velocities, but exhibit a much wider range in effective densities than the larger macro-flocs. The sizes and settling velocities of flocs are key parameters when modeling cohesive sediment transport in near-shore waters (Manning and Schoellhamer, 2013). Thus, it is necessary to predict accurately the size of the flocs and their settling velocities in order for accurate estimations of the transport of cohesive sediment.

Direct measurement of floc size distribution in wave-dominated environments is difficult, and therefore the number of attempts for such observations is few, and they exhibit uncertainties. Main source of uncertainty is the limited functionality of the instruments (e.g., LISST: Laser In Situ Scattering Transmissometer) at relatively high concentrations, constraining the deployment only at locations (high in the water column) where the concentration is expected to be low (e.g., Sahin et al., 2013; Safak et al., 2013; Sahin, 2014). More importantly, these measurements are not representative for the water column processes since floc size varies vertically due to varying flow and sediment conditions (Dyer, 1989; Dyer and Manning, 1999; Winterwerp, 1999; Verney et al., 2011; Safak et al., 2013; Sahin, 2014, and many others). Acoustic techniques have been used recently to estimate both suspended sediment concentration (SSC) and floc size with high vertical resolution from the acoustic intensity records at multiple frequencies (Sahin, 2014). However, this procedure requires supportive independent point measurements of floc size and SSC synchronously collected with the acoustic backscatter measurements at different frequencies. A few studies published so far (e.g., Gartner, 2004; Ha et al., 2011; Sahin et al., 2013; Sahin, 2014; Thorne et al., 2014) on the use of acoustic backscatter systems to study cohesive sediment transport acknowledge the difficulty and uncertainty of interpretation of the acoustic observations.

All flocculation models, developed for quantitative prediction of floc size, floc density and settling velocity in the bottom boundary layer, are based on some version of the aggregation-fragmentation equation (e.g., Drake, 1972; Ball and Carr, 1990), which expands the coagulation equation originally proposed by Smoluchovsky (1917). While the basic flocculation principles are generally agreed upon, the flocculation debate 
and contributions (e.g., McAnally and Mehta, 2000; Maggi et al., 2007; Lee et al., 2011; Verney et al., 2011) seem to be focused on the role and form of particular terms, such as turbulence-induced collision and breakup processes (Maggi et al., 2007), or shear aggregation (Winterwerp et al., 2006; Manning and Dyer, 2007; Verney et al., 2011; Soulsby et al., 2013). To reduce computational costs, some models focus on simplified distributions (e.g., bimodal, Lee et al., 2011). With a few exceptions (e.g., Lee et al., 2011), most models assume homogeneous and isotropic suspensions (so-called 0-D models), and neglect settling effects and boundary sediment sources. While these models can resolve many mechanisms causing flocculation, only a few of them were coupled with cohesive sediment transport models, related to the limitations due to computational costs, increasing model complexity, difficulty of parametrization and the lack of knowledge on processes affecting floc properties like fractal dimension, size and density.

This paper represents an effort to investigate the effect of flow and sediment related parameters on cohesive sediment flocculation in a wave-energetic environment from both observational and modeling points of view. Field observations are based on a wide range of wave-current conditions and sediment concentrations collected in a shallow area on the muddy Atchafalaya inner shelf, Louisiana (Section 2). Vertical profiles of the physical parameters affecting flocculation (e.g., turbulent intensity and SSC) are extracted from the near-bed velocity and backscatter measurements (Section 3). We also propose a new modeling approach, the use of ANN, for estimation of vertical profiles of floc size (Section 4). Artificial neural networks (ANN) can be an alternative technique for modeling of processes in which the interrelationship of parameters is unclear while sufficient experimental data is available to identify such relations. These properties of ANN are suitable for prediction of floc sizes which is influenced by many random variables. Model results are used in conjunction with the field observations for a detailed description of flocculation processes in the water column. The implications of the results are discussed in relation to the response of suspended cohesive sediments to hydrodynamic forcing and the significance of the findings on sediment dynamics at the site (Section 5). 


\section{Field experiment}

\subsection{Study site and instrumentation}

The field data set was collected by an instrumented platform deployed near the 5-m isobath on the muddy inner shelf fronting the Atchafalaya Bay in the northern Gulf of Mexico over a one-week period between March 3rd and March 11th, 2006 (time reported in this study is UTM) (Fig.1a). The representative grainsize on the muddy, nearly flat (maximum slope less than 1:1000) inner shelf ranges between 2 and $7 \mu \mathrm{m}$, with 17\% fine-sand content (Sheremet et al., 2005; Safak et al., 2010). Sediment loaded fresh water plume associated with the Atchafalaya River discharge brings approximately 84 metric tons per year of sediment (Mossa, 1996). In addition, between December and April, energetic waves associated with cold atmospheric fronts rework the bed, mobilizing large quantities of sediment. These two competing processes cause the formation of near-bed fluid mud layers, which move onshore and offshore over the submerged river delta (Sahin et al., 2012). The observations presented here is a part of a larger-scope study of hydrodynamics and sediment transport processes in shallow muddy environments. The reader is referred to Jaramillo et al. (2009) for detailed description of the field conditions during the 2006 experiment and the sediment type distribution on the Atchafalaya Shelf (see their Fig. 2).

Configuration of the instrumented platform is shown schematically in Fig. 1b. The vertical structure of the flow velocity in the first mab (meter above the bed) was measured using a PC-ADP (Pulse-Coherent Acoustic Doppler Profiler, Sontek/YSI), that sampled at 2-Hz in 60 bins of $2 \mathrm{~cm}$ with a 10-cm blanking distance in 10-min bursts every 30-min. Direct SSC observations were provided by two OBS-3s (Optical Backscatterance Sensors, D\&A Instruments, Campbell Sci.) that sampled synchronously with the PC-ADP at 50 and $75 \mathrm{cmab}$ ( $\mathrm{cm}$ above the bed). The OBS-3s were calibrated in the laboratory using sediment and water samples collected at the experimental site. Grain-size distributions of suspended sediments were estimated based on the observations of a LISST-100X Type-C (Laser In Situ Scattering Transmissometer, Sequoia Scientific) mounted at $120 \mathrm{cmab}$ which estimates size distributions of suspended particles (flocs and primary) at 32 class ranges between $2.5-500 \mu \mathrm{m}$. The instrument recorded the grain-size distribution of suspended sediment every minute (average of 100, 2-Hz samples) in 30-min bursts each hour. A Seabird MicroCAT at 115 cmab sampled salinity and temperature synchronously with the PC-ADP.

The PC-ADP pressure time series segments of 10-min length were de-trended and de-meaned, then divided 
into 128 s blocks with 50\% overlap, and tapered using a Hanning window. The resulting spectra have approximately 17 degrees of freedom. The significant wave-height $H_{s}$ was estimated based on the relation $H_{s}^{2}=16 \int_{f_{1}}^{f_{2}} S_{\eta \eta}(f) d f$ where $S_{\eta \eta}$ is the power spectral density of sea surface elevation $\eta$ at frequency $f$, estimated using standard spectral analysis. $S_{\eta \eta}$ was corrected for depth attenuation using the linear wave theory, with a high-frequency cutoff defined by a depth attenuation of wave variance larger than $95 \%$. A spectral tail proportional to $f^{-5}$ was added to cover the high frequency range. Swell (long waves) and sea (short waves) bands were distinguished by using a cutoff frequency of $f_{c}=0.2 \mathrm{~Hz}$, e.g., for swell band $f_{1}=$ $0.0078 \mathrm{~Hz}, f_{2}=f_{c}$; for sea band $f_{1}=f_{c}, f_{2}=0.992 \mathrm{~Hz}$. Representative flow and sediment statistics (mean speed and direction of currents, wave spectrum, significant wave height, mean concentration, salinity, temperature and mean floc size) were calculated for one-hour intervals, resulting in a 195-point time series of mean values for measured data.

\subsection{Observations}

Observations of the evolution of flow and sediment characteristics within the March 3-11, 2016 period are summarized in Fig. 2. Seas (wind waves), sometimes reaching $1 \mathrm{~m}$ significant heights, are observed over the one-week period (Fig. 2a). Swell activity is appeared to be negligible during the first 5 days. Starting from the evening of March 8th, swell energy increases significantly, coinciding with a significant increase in current speed that exceeds $0.4 \mathrm{~m} / \mathrm{s}$ within the profiling range of the PC-ADP (Fig. 2b). In general, SSC variations appear to be correlated to wave-current activity. When strong swell activity periods coincide with strong currents, a significant bed sediment resuspension appears to have triggered as the OBSs measured the highest concentration values, reaching almost $8 \mathrm{~kg} / \mathrm{m}^{3}$ at $50 \mathrm{cmab}$ (Fig. $2 \mathrm{a}, \mathrm{b}$ and c).

The grain-size distribution (given as fractional volume of particles in $\mu \mathrm{L} / \mathrm{L}$, see Fig. $2 \mathrm{~d}$ ) recorded by the LISST is bi-modal with a dominant floc-mode, that spans the $150-300 \mu \mathrm{m}$ range, with the peak position between 200 and $230 \mu \mathrm{m}$; and a weaker floc-mode positioned around $50 \mu \mathrm{m}$. The position of the peaks of two modes are remarkably stable, in spite of the varying flow conditions (Fig. 2a, b and d). The dominant grain-size is in the range of coarse sand, however, because there is not coarse sand in this region, we interpret it to represent the floc mode (Safak et al., 2010). The mean floc size extracted from the grain size distribution varies between $25 \mu \mathrm{m}$ and $300 \mu \mathrm{m}$ with the average around $200 \mu \mathrm{m}$ (Fig. 2e). Variations in the mean floc size seem to be negatively correlated to flow conditions and the amount of sediment in suspension. This 
indicates that conditions become favorable to floc growth during calm periods, characterized with weak waves-currents and low SSC. Suspended sediments are mainly small flocs during energetic periods, probably due to strong turbulence causing floc breakage (Fig. 2a-e). Salinity and temperature vary between 25-29 psu and $18-21{ }^{\circ} \mathrm{C}$, respectively, throughout the period of interest. Especially, an inverse relation is apparent between temperature and floc size variations (Fig. 2e and f), suggesting that thermal energy might also play a role on the flocculation processes.

\section{Data analysis}

A number of field and laboratory studies have highlighted relationships between floc size, flow turbulence and sediment concentration, confirming the well known conceptual diagram by Dyer (1989). All of these parameters likely vary vertically. Optical sensors (such as the ones used in this study) provide a few SSC measurement points that are in general not dense enough for a satisfactory characterization of the sediment content in the water column. Since commercial current profilers are commonly used to measure current and backscatter intensity profiles, vertical distributions of the parameters controlling floc formation (e.g., turbulent shear and SSC) may be extracted from the current velocity profiles; which can then be used as input for the ANN model to estimate the vertical floc size profiles.

\subsection{Estimation of shear rate}

It is known that the flow turbulence is one of the dominant mechanisms controlling floc formation (e.g., Dyer, 1989; Verney et al., 2011; Safak et al., 2013; Sahin, 2014) and can be represented by the shear rate $G$ $\left(\mathrm{s}^{-1}\right)($ Berhane et al., 1997; Dyer and Manning, 1999; Safak et al., 2013; Sahin, 2014),

$$
G=\left(\frac{\varepsilon}{v}\right)^{1 / 2}
$$

where $v$ is the kinematic viscosity of the fluid, $\varepsilon=\frac{u_{*}^{3}}{\kappa z}$ is the dissipation rate with $u_{*}$ the friction velocity, $\kappa=0.41$ the von Karman's constant and $z$ the distance above bed. Assume a logarithmic law of the wall for unstratified turbulent boundary layer

$$
u(z)=\frac{u_{*}}{\kappa} \ln \left(\frac{z}{z_{0}}\right),
$$


where $u$ is the horizontal velocity, and $z_{0}$ is a function of bottom roughness at which the velocity is zero. The parameters $u_{*}$ and $z_{0}$ in Eq. 2 can be estimated iteratively based on the values providing the best-fit between logarithmic profiles and the measured current velocity profiles $u(z)$ outside the wave boundary layer (Lacy et al., 2005; Safak et al., 2013). The reader is referred to Lacy et al. (2005) and Safak et al. (2013) for further details about the procedure.The method was applied to the PC-ADP velocity profiles throughout the period of interest in order to calculate the friction velocity $u_{*}$, and therefore the bottom shear stress $\tau_{b}=\rho u_{*}^{2}$, where $\rho$ is the fluid density (Fig. 3a and b). Since the thickness of the wave boundary layer is typically no more than a few $\mathrm{cm}$, the first two bins above the bed were not included in the analysis. The $u_{*}$ estimates were then used to calculate the dissipation rate and the shear rate throughout the vertical axis using Eq. 1 (Fig. 3c). The valid logarithmic zone spanned the entire profile for $75 \%$ of the measurement bursts (146 of the 195 bursts) with an average $r^{2}=0.97$. The estimated bottom shear stresses were between almost nil and 0.5 Pa., largely following the variations in current speed (Fig. 3a and b). The vertical profiles of $G$ estimates are seen in Fig. 3c, which will be used to investigate the effect of turbulence intensity on floc size.

\subsection{Estimation of SSC profiles}

Vertical profiles of SSC are estimated based on the acoustic backscatter intensity data of the PC-ADP, calibrated using independent OBS observations at 50 and $75 \mathrm{~cm}$ above the bed. The calibration involves estimation of a PC-ADP 'system constant' that yields the best agreement between concentrations measured by an independent instrument (OBS, herein) and PC-ADP estimates. The transmission losses, which consist of losses arising from spherical spreading of the beams and attenuation due to water and sediment, added to the raw backscatter for the correction. Due to the spherical spreading a near field correction factor has to be introduced to include this effect. Sound attenuation by water per unit travel length is a function of acoustic frequency, salinity, water temperature, and pressure. In shallow water (depth $<20 \mathrm{~m}$ ), pressure is not sufficient to exert a significant effect on the attenuation coefficient. The sediment attenuation can be calculated for known SSC profiles. If the SSC profile is not known, for dilute concentrations it can be assumed negligible. However, in high concentrations (e.g., $>1 \mathrm{~kg} / \mathrm{m}^{3}$ ) such as those observed in this study (Section 2.2), sediment attenuation has to be taken into account. The resulting implicit problem is solved for SSC using an iterative approach (e.g., Thorne and Hanes, 2002). Details of the conversion algorithm and the calibration procedure are not given here since the related information was given in detail in Sahin et 
al. (2013) for the data set presented in this study. The values of SSC estimated from backscatter (Fig. 8a) showed a good agreement with the OBS-3 observations with an average root-mean square error of $\varepsilon=0.14$ $\mathrm{kg} / \mathrm{m}^{3}$ and correlation coefficient of $r=0.87$ (Sahin et al., 2013).

\section{Modeling}

\subsection{Artificial neural networks}

Artificial neural networks are based on imitation of biological functions, reflecting the ability to solve problems by learning the cases by referring to the existing samples and producing suitable responses for new situations. Similar to a human brain, an ANN uses several computational elements, called artificial neurons, connected by variable weights. While a single neuron is capable of performing only simple calculations, the hierarchical organization of a network of interconnected neurons makes an ANN capable of performing complex tasks such as pattern classification and prediction. Therefore, they can efficiently tackle the lack of linearity and the multivariate behavior, even when the governing interrelationships of the variables are unknown. Basic structure of an artificial neural network model is composed of three layers, i.e., input, hidden, and output layer, which are connected by links with varying weights. The nodes of one layer are connected to the nodes of another layer with connection weight but not connected to nodes of the same layer. The inputs of the nodes in one layer come from the outputs of nodes in a previous layer. The connection weights between nodes are optimized using the known input and target values through an iterative process and error-minimization technique, so that the network produces outputs close or equal to the known target values. The process is called training of the network. However, due to the black-box nature of ANN models, the learned relationship between the inputs and output is not revealed and can only be tested with a new instance. This requires cautious usage of the new model, and it should not be used beyond the ranges of the data for which it was trained (Bhattacharya et al., 2005; Sahin et al., 2016).

\subsection{Model architecture and development}

This study utilizes a multi-layer feed-forward network consisting of one input layer, one hidden layer, and one output layer to create the neural network to estimate floc sizes. Feed-forward ANN models with back 
propagation training algorithm and the hyperbolic tangent sigmoid activation function in the input and output nodes were used. The number of nodes in the input layer is fixed by the number of explanatory variables with available data known to have an impact on flocculation (SSC, shear rate, salinity and temperature). Unfortunately, there was no available data for other parameters affecting flocculation such as mineralogy (Winterwerp and van Kesteren, 2004) and organic content (Kranck, 1984), and therefore they were not included in the input layer. Since the primary particle size was assumed constant and taken as $D_{p}=5 \mu \mathrm{m}$ based on previous studies (Jaramillo et al., 2009; Safak et al., 2010; Sahin et al., 2012), it was not selected as an explanatory variable, either. One node in the output layer represents the mean floc size (Table 1, Fig. 4). The Levenberg-Marquardt method (Levenberg, 1944; Marquardt, 1963) was used to train the ANN by updating the connection weights based on a mean square error metric (Demuth et al., 2007). The LevenbergMarquardt (LM) algorithm is an iterative technique that locates the minimum of a multivariate function that is expressed as the sum of squares of non-linear real-valued functions. In back propagation networks, the error between the target output and the network output is calculated and is back-propagated using the steepest descent or the gradient-descent approach. In the current work, the gradient-descent approach was used. Running the training algorithm for too long may lead to over-training, and hence to poor performance for inputs other than those used in training. On the other hand, stopping the training algorithm too soon leads to under-trained ANNs. Here, the number of iterations was limited to ten epochs in order to avoid both over- and under-training the model. Similarly, the number of nodes in the hidden layer is dependent on the amount of available data and the number of explanatory variables. A greater number of hidden neurons provides an increased degree of flexibility in the model, however runs the risk of over-fitting (Bishop, 1995). Although many methods have been suggested for determining the correct number of neurons to be used in the hidden layer, there is no generalized rule to select the number of hidden layer neurons, and selection of it is problem specific (Panchal et al., 2011; Sheela and Deepa, 2013). In order to determine the optimum number of hidden neurons in this study, we repeated testing by increasing the number of neurons until the test error does not improve anymore.

Since the floc size measurements, which form the output layer data, were available at $1.2 \mathrm{mab}$ (meter above the bed), we used the input layer data collected at the closest vertical level in development of the model, i.e., SSC and shear rate estimates at the first PC-ADP bin (approximately $1 \mathrm{mab}$ ), salinity and temperature measured at 1.1 mab (Fig. 1b, Fig. 5a-d). Variation of the flow and sediment conditions were assumed 
negligible within the $20-\mathrm{cm}$ distance between these data locations. The available data were divided into three subsets: training, validation and test data. We took 70 percent of the input data for training, which correspond to 102 samples out of total 146 samples with valid shear rate estimates. The remaining two sets of 22 samples (15 percent) were kept for validation and testing, respectively. In selection of the subsets, it was made sure that they include the samples representing different physical conditions (calm, moderate and energetic conditions) (Fig. 5e).

The performance of the model for increased hidden layer neurons was analyzed in order to determine the optimum number of neurons in the hidden layer. Correlation between the measured floc sizes and the model results increased with increasing number of hidden neurons up to ten neurons. With ten neurons in the hidden layer, the performance of the model for the training-validation data and the test data were remarkably close with $r=0.9$. Increasing hidden layer neurons more than ten did not improve the model results both for training-validation, and the test data (Fig. 6a). Calculated RMS (root-mean square) errors showed a similar behavior. While the errors decreased with increasing hidden layer neurons up to ten neurons, using more than ten hidden neurons in the hidden layer did not improve the model performance (Fig. 6b). With ten hidden layer neurons, the RMS error values are the closest for different data subsets. Therefore, the model with one hidden layer with ten neurons was selected as the optimum alternative to be used in this study. Mean floc sizes calculated by the ANN model agree well with the measurements for both the training-validation and the test data with an average correlation coefficient of $r=0.9$, and an average root-mean square error of $\varepsilon=35.5 \mu \mathrm{m}$ (Figs. 5e and 7).

\section{Results and discussion}

Once the model was built with the measurements at about 1-m above the bed, vertical mean floc size profiles were modeled using the vertical profiles of the input parameters. The values of SSC and $G$ corresponding to each PC-ADP cell were used as inputs with a $2 \mathrm{~cm}$ vertical resolution (Fig. 8a and b). Since only the point measurements of salinity and temperature were available, these parameters were assumed to be vertically constant, e.g., salinity and temperature measured at $115 \mathrm{cmab}$ were assumed to represent the water column values (Fig. 8c and d). Fig. 8e shows the time evolution of the resulting mean floc size profiles from the newly developed ANN model. Data gaps in the vertical floc size estimates correspond either to the time 
segments with invalid $G$ estimates based on the log-fit velocity profiles, or to the data points in which the input data (Fig. 8a-d) are beyond the values used in model development (Fig. 5a-d, Section 4.2). In the vertical direction, resulting floc size values show a decreasing trend toward the bed, where both SSC and shear rate are high. In general, the largest floc size estimates are seen during the first half of the observation period during which SSC, $G$ and water temperature are relatively low and the salinity is relatively high. While floc size evolution does not indicate a clear correlation to the salinity observations, it seems inversely related to the water temperature, indicating the impact of thermal energy on flocculation.

The modeled floc size profiles allow for a detailed investigation of the interplay between floc size, SSC and turbulence. Fig. 9 assembles the estimates of shear rate, suspended sediment concentration and floc size. A linear correlation $(r=0.49)$ is observed between SSC and $G$, especially for low and moderate SSC and $G$, indicating that the amount of sediment is controlled by the turbulence level (also see Fig. 8a and b). A few data points corresponding to the moderate turbulent shear $\left(\sim 2-2.4 \mathrm{~s}^{-1}\right)$, highest SSC $\left(\sim 2 \mathrm{~kg} / \mathrm{m}^{3}\right)$ and lowest floc size $(\sim 40 \mu \mathrm{m})$ conditions fall outside of this linear relationship. The study site is impacted by a sediment-laden fresh water plume from the Atchafalaya River mouth, indicating a horizontal sediment-flux convergence (Sahin et al., 2012). These data likely correspond to the high river discharge periods during which, in addition to the impact of local turbulence, sediment advected from the Atchafalaya River further increases the SSC. Formation of large flocs is possible when SSC and $G$ are both low, e.g., flocs of larger than $160 \mu \mathrm{m}$ (macro-flocs, i.e., highly porous, fragile, fast settling aggregates) are consistently formed when $G$ is lower than $1 \mathrm{~s}^{-1}$ and SSC is lower than $0.6 \mathrm{~kg} / \mathrm{m}^{3}$. Floc size values decrease as both $G$ and SSC increase, indicating that the formation of large flocs is not possible under high shear and high SSC conditions. Smallest flocs $(D<\sim 50 \mu \mathrm{m})$ are formed either under the strongest turbulence $\left(G>3.5 \mathrm{~s}^{-1}\right)$ and/ or under the highest SSC conditions $\left(\mathrm{SSC}>1.8 \mathrm{~kg} / \mathrm{m}^{3}\right)$.

Fig. 10 shows the variation of floc size with sediment concentration and shear rate separately. Floc size shows a general decreasing trend with both increasing SSC and increasing shear rate, with a stronger relationship with SSC (Fig. 10a, $r=0.69$ ) than shear rate (Fig. 10b, $r=0.41$ ). However, the rate of decrease slows down as SSC and the shear rate increase. Smaller flocs occur at higher turbulence levels and suspended sediment conditions (Fig. 10a and b). The fact that the large flocs are not formed under high shear conditions suggests that floc strength, the resistance to breakup by fluid shearing and collision-induced forces, decreases with increasing floc size. This supports the previous studies that show the strength of the floc is 
inversely proportional to the square of the floc size (Al Ani et al., 1991; Winterwerp, 1999; McAnally and Mehta, 2002).

A more detailed examination of these results can be made using the vertical profiles of parameters affecting the flocculation processes. Fig. 11 exhibits vertical profiles of SSC, shear rate and mean floc size representing two distinct flow and sediment conditions. Under high-energy (represented by strong wave-current activity, dashed line in Fig. 11a) and low-energy (represented by weak wave-current activity, solid line in Fig. 11a) conditions, sediment concentration increases toward the bed and reaches near-bed values of around $20 \mathrm{~kg} / \mathrm{m}^{3}$ and $10 \mathrm{~kg} / \mathrm{m}^{3}$, respectively. Shear rate also shows a similar behavior with corresponding near-bed values of $10 \mathrm{~s}^{-1}$ (dashed line in Fig. 11b) and $3 \mathrm{~s}^{-1}$ (solid line in Fig. 11b), respectively. For both highand low-energy conditions, $G$ decreases upwards significantly within the first $\sim 10 \mathrm{~cm}$ above the sea bed, where the concentrations are high. This drastic decrease in $G$ indicates high viscous dissipation in this layer based on Eq. 1. This modification of the flow turbulent structure is attributed to the development of sediment induced vertical density stratification, which becomes more apparent at high concentrations (Cloutier et al., 2006; Sahin et al., 2013; Sahin, 2014). Presence of high concentrations of cohesive particles lead to plastic-like behavior, with significant increase in apparent bulk viscosity (Leeder, 1999). This increase in suspension viscosity subsequently causes the viscous dissipation rate of turbulent kinetic energy in the carrier fluid to be increased (Toorman et al., 2002). Therefore, sediment suspension increases mean flow energy loss and decreases turbulence intensity in the vertical direction (Guo and Julien, 2001).

Vertical variation of floc size shows the opposite behavior than SSC and shear rate (Fig. 11c). Under both high- and low-energy conditions, the floc size decreases toward the bottom, suggesting floc breakage due to increasing turbulence intensity toward the bed. Near the bed, high turbulence results in floc breakage while high SSC causes the dissipation of turbulence intensity. In all the vertical levels, flocs are smaller under the high-energy conditions (dashed line in Fig. 11c), characterized with high concentration and high turbulence, suggesting that calmer flow conditions and lower sediment concentrations are favorable to aggregation in energetic environments such as the Atchafalaya Shelf.

These results agree with the concept of a cohesive sediment particle undergoing aggregation processes (Mehta, 1991; McAnally and Mehta, 2000), a floc in suspension experiencing aggregation-fragmentation processes in the water column may bond with other particles and break apart from them. As the aggregate grows larger, the settling velocity increases. It settles toward the bed and enters a stirred layer of high sed- 
iment concentration and high shear. In this stirred layer, if the floc integrity is less than the ambient shear stresses, the floc will fracture under the forces due to turbulent fluctuations and collisions with other particles (see decrease in floc size toward the bed in Fig. 11).

The LISST has a limited functionality in the relatively high near-bed concentrations, therefore we trained and validated the ANN model with floc size measurements at one vertical level (high in the water column) where the concentration is expected to be low. Floc size measurements at different vertical locations would improve the model calibration. Additionally, the LISST measures a floc as a single particle, i.e., it cannot distinguish large low density macro-flocs from higher density sand grains of a similar size. The dominant grain-sizes measured in this study are in the range of coarse sand, however, because there is not coarse sand in this region, we interpret it to represent the floc mode (Safak et al., 2010).

\section{Conclusions}

The effect of flow and sediment conditions on cohesive sediment flocculation is investigated using both high-resolution field observations and the newly developed model based on artificial neural networks on the wave-energetic muddy coast of Atchafalaya Shelf, Louisiana, USA. Field observations involve vertical current and backscatter profiles, and point measurements of SSC, particle size distribution, salinity and temperature. Vertical variations of some important parameters known to be efficient on flocculation processes were extracted from the PC-ADP measurements, e,g., suspended sediment concentration and shear rate. The vertical structure of suspended sediment concentration is estimated by calibrating the acoustic backscatter intensity, following the algorithm described in Sahin et al. (2013). Turbulent shear profiles were estimated using the current velocity profiles. The friction velocities were estimated by fitting the logarithmic profiles in a least-square sense to the current velocity profiles, outside the wave boundary layer, which can then be used to approximate the dissipation of turbulent kinetic energy and the turbulent shear profiles (Lacy et al., 2005). Temperature and salinity were assumed vertically constant since only the point measurements of these parameters were available. The ANN model to estimate the mean floc size was validated and tested using the observations at around 1 mab. The calibrated model was then used to estimate the water column processes of flocculation.

Resulting floc size values show a decreasing trend toward the bed as both SSC and turbulence intensity get 
higher. A linear correlation is observed between suspended sediment concentration and the turbulence intensity. General inverse relationships are seen between floc size and concentration, floc size and turbulence intensity, and floc size and water temperature. Observations and the model results suggest no clear correlation of floc size to the salinity. Macro-floc $(D>160 \mu \mathrm{m})$ formation is possible when SSC and G are both low, i.e., $G<1 \mathrm{~s}^{-1}$ and $\mathrm{SSC}<0.7 \mathrm{~kg} / \mathrm{m}^{3}$, indicating that floc growth is promoted by low concentrations and low turbulence. This also indicates that the strength of the floc, the resistance to breakup by fluid shearing and collision-induced forces, decreases with increasing floc size. The results suggest that a drastic decrease in turbulent shear could occur within the bottom few-cm, related to increased damping of turbulence by sediment induced density stratification, resulting in floc breakage in this highly turbulent layer. While increasing turbulence increases the amount of sediment in the water column, it causes a decrease in the mean floc size, indicating floc breakage.

The observations and the model results are consistent, and agree with the concept of a cohesive sediment particle undergoing aggregation processes in literature (Mehta, 1991; McAnally and Mehta, 2000), suggesting that the ANN can be an alternative precise tool to study flocculation processes. Despite promising results, more comprehensive data sets are needed to be included in calibration covering the observations of other parameters affecting flocculation such as mineralogy, organic content, and vertical profiles of salinity and temperature. Future efforts should aim at improving the ANN models with such data, and coupling them with cohesive sediment transport models.

\section{Acknowledgments}

This research was supported by the Office of Naval Research funding of contracts N00014-10-1-0363 and N00014-11-1-0269. Dr. Ilgar Safak, Dr. Sergio Jaramillo, Uriah M. Gravois and the field support group of Coastal Engineering Laboratory of University of Florida helped in the deployment and retrieval of the instruments. The author thanks the two anonymous reviewers for their insightful and constructive comments that improved the manuscript. 


\section{References}

Al Ani S, Dyer KR, Huntley DA. Measurement of the influence of salinity on floc density and strength. Geo-Marine Letters (1991); 11, 154-158.

Ball JM, Carr J. The Discrete Coagulation-Fragmentation Equations: Existence, Uniqueness, and Density Conservation, Journal of Statistical Physics (1990); 61(1/2), 203-234.

Berhane I, Sternberg RW, Kineke GC, Milligan TG, Kranck, K. The variability of suspended aggregates on the Amazon Continental Shelf. Cont Shelf Res (1997); 17, 267-285.

Bhattacharya B, Price RK, Solomatine DP. Data driven modelling in the context of sediment transport. Physics and Chemistry of the Earth, Part A Solid Earth and Geodesy (2005); 30 (4-5): 297-302.

Bishop CM. Neural networks for pattern recognition. Oxford: Clarendon Press (1995).

Buchanan PA, Schoellhamer DH. Summary of suspended solids concentration data, San Francisco Bay, California, Water Year 1997. USGS OFR (1999); 99-189, 52 pp.

Burban PY. The flocculation of fine-grained sediments in estuarine waters. MSc. thesis (1987); Dep. of Mech. Eng. Univ. of Calif., Santa Barbara, USA.

Burban P-Y, Xu Y-J, McNeil J, Lick W. Settling speeds of flocs in freshwater and seawater. Journal of Geophysical Research (1990); 95, 18,213- 18,220.

Cloutier D, LeCouturier MN, Amos CL, Hill PR. The effects of suspended sediment concentration on turbulence in an annular flume. Aquatic Ecology (2006); 40 (4), 555-565, doi:10.1007/s10452-005-4810-2.

Dearnaley, MP. Flocculation and settling of cohesive sediments. Technical Report. HR Wallingford (1991).

Demuth, H., Beals, M., Hagan, M. Neural Network Toolbox 5 User's Guide. The Mathworks, Inc, Natick, Massachusetts, USA (2007).

Drake R. In Topics in Current Aerosol research, G.M. Hidy and J.R. Brock, eds., Pergamon Press, Oxford, (1972).

Dyer KR. Sediment processes in estuaries: future research requirements. J Geophys Res (1989); 97, $14327-14339$. 
Dyer KR, Manning AJ. Observation of size, settling velocity and effective density of flocs, and their fractal dimensions. J Sea Res (1999); 41, 87-95.

Eisma D. Flocculation and de-flocculation of suspended matter in estuaries. Netherlands Journal of Sea Research (1986); 20 (2/ 3), 183-199.

Fitzpatrick CSB, Fradin E, Gregory J. Temperature effects on flocculation, using different coagulants. Water Science and Technology (2004); 50 (12) pp.

Gartner JW. Estimating suspended solids concentrations from backscatter intensity measured by acoustic Doppler current profiler in San Francisco Bay, California. Mar Geol (2004); 211 (3), 169-187.

Guo J, Julien PY. Turbulent velocity profiles in sediment-laden flows. Journal of Hydraulic Research (2001) 39:1, 11-23, doi: 10.1080/00221680109499798.

Ha HK, Maa JP -Y, Park K, Kim YH. Estimation of high-resolution sediment concentration profiles in bottom boundary layer using pulse-coherent acoustic Doppler current profiles, Mar Geol (2011); 279, 199-209.

Hammond DE, Fuller CC, Harmon DD, Hartman B, Korosec M, Miller LG, Rea R, Warren S, Berelson W, Hager SW. Benthic fluxes in San Francisco Bay, Hydrobiologia (1985); 129: 69-90.

Jaramillo S, Sheremet A, Allison MA, Reed AT, Holland KT. Wave-mud interactions over the muddy Atchafalaya subaqueous clinoform, Louisiana, USA: Wave-driven sediment transport. J Geophys Res (2009); 114, C04002, doi: 10.1029/2008JC004821.

Kranck K. The role of flocculation in the filtering of particulate matter in estuaries. In: Kennedy, V. (ed.), The Estuary as a Filter. Academic. Press, London: 159- 175 (1984).

Krone RB. Flume Studies of the Transport of Sediment in Estuarial Shoaling Process: Final Report, Hydraulic Engineering Laboratory and Sanitary Engineering Research Laboratory, University of California, Berkeley, California (1962); 110 pp.

Kuwabara JS, Chang CCY, Cloern JE, Fries TL, Davis JA, Luoma SN. Trace metal associations in the water column of South San Francisco Bay, California. Estur Coast Shelf S (1989); 28, 307-325. 
Lacy JR, Sherwood CR, Wilson DJ, Chisholm TA, Gelfenbaum GR. Estimating hydrodynamic roughness in a wave-dominated environment with a high-resolution acoustic Doppler profiler. J Geophys Res (2005); 110, C06014, doi: 10.1029/2003JC001814.

Lau YL. Temperature effect on settling velocity and deposition of cohesive sediments, Journal of Hydraulic Research (1994); 32, pp. 41 - 51.

Lee BJ, Toorman E, Molz FJ, Wang J. A two-class population balance equation yielding bimodal flocculation of marine or estuarine sediments. Water Res (2011); 45, 2131-2145.

Leeder MR. Sedimentology and Sedimentary Basin: from turbulence to tectonics, Blackwell Science Oxford, UK (1999); $592 \mathrm{p}$.

Levenberg K. A method for the solution of certain non-linear problems in least squares. Quarterly of Applied Mathematics (1944); 2, 164-168.

MacDonald IT, Vincent CE, Thorne PD, Moate PD. Acoustic scattering from a suspension of flocculated sediments. J Geophys Res-Oceans (2013); 118(5): 2581-2594.

Maerz J, Verney R, Wirtz K, Feudel U. Modeling flocculation processes: intercomparison of a size classbased model and a distribution based-model. Cont Shelf Res (2011); 31: S84-S93.

Maggi F, Mietta F, Winterwerp JC. Effect of variable fractal dimension on the floc size distribution of suspended cohesive sediment. J Hydrol (2007); 343(1-2): 43-55.

Manning AJ. A study of the effects of turbulence on the properties of flocculated mud. Ph.D. Thesis (2001); Institute of Marine Studies, University of Plymouth, 282p.

Manning AJ, Dyer KR. A laboratory examination of floc characteristics with regard to turbulent shearing. Marine Geology (1999); 160: 147-170.

Manning AJ. The observed effects of turbulence on estuarine flocculation. In: P. Ciavola and M. B. Collins (Eds), Sediment Transport in European Estuaries, Journal of Coastal Research (2004); SI 41, 90-104.

Manning AJ, Dyer KR. Mass settling flux of fine sediments in Northern European estuaries: measurements and predictions. Marine Geology (2007); 245, 107-122, doi:10.1016/j.margeo.2007.07.005. 
Manning AJ, Schoellhamer DH. Factors controlling floc settling velocity along a longitudinal estuarine transect. Mar Geol (2013); 345: 266-280.

Marquardt D. An algorithm for least-squares estimation of nonlinear parameters. SIAM Journal on Applied Mathematics (1963); 11, 431-441.

McAnally WH, Mehta, AJ. Aggregation rate of fine sediment. Journal of Hydraulic Engineering (2000); $126,883-892$.

McAnally WH, Mehta AJ. Significance of aggregation of fine sediment particles in their deposition. Estuar Coast Shelf S (2002); 54: 643-653.

McCave IN. Size spectra and aggregation of suspended particles in the deep ocean. Deep-Sea Res (1984); 31: 329-352.

Mehta, AJ. Review notes on cohesive sediment erosion. Coastal Sediments '91, (N. C. Kraus, K. J. Gingerich, and D. L. Kriebel, eds.), ASCE, Reston (1991); Va. 40-53.

Mehta, AJ. An Introduction to Hydraulics of Fine Sediment Transport. Advanced Series on Ocean Engineering: Volume 38, Springer (2013); 1060pp.

Mossa, J. Sediment dynamics in the lowermost Mississippi River. Engineering Geology (1996); 45, 457479.

Panchal G, Ganatra A, Kosta YP, Panchal D. Behaviour analysis of multilayer perceptrons with multiple hidden neurons and hidden layers. International Journal of Computer Theory and Engineering (2011); vol. 3, no. 2, pp. 332-337.

Safak I, Sheremet A, Allison M A, Hsu T-J. Bottom turbulence on the muddy Atchafalaya Shelf, Louisiana, USA. J Geophys Res-Oceans (2010); 115, doi:10.1029/2010JC006157.

Safak I, Allison MA, Sheremet A. Floc variability under changing turbulent stresses and sediment availability on a wave energetic muddy shelf, Cont. Shelf Res (2013); 53, 1-10, http://dx.doi.org/10.1016/j.csr.2012.11.015.

Sahin C, Safak I, Sheremet A, Mehta AJ. Observations on cohesive bed reworking by waves: Atchafalaya Shelf, Louisiana. J Geophys Res-Oceans (2012); 117, doi:10.1029/2011JC007821. 
Sahin C, Safak I, Hsu T-J, Sheremet A. Observations of suspended sediment stratification from acoustic backscatter in muddy environments. Mar Geol (2013); 336, 24-32, http://dx.doi.org/10.1016/j.margeo.2012.12.001.

Sahin, C. Investigation of the variability of floc sizes on the Louisiana Shelf using acoustic estimates of cohesive sediment properties. Mar Geol (2014); 353, 55-64, http://dx.doi.org/10.1016/j.margeo.2014.03.022.

Sahin C, Guner HA, Ozturk M, Sheremet A. Modeling Flocculation Processes Using Artificial Neural Networks. ISOPE-2016, The 26th International Ocean and Polar Engineering Conference (2016); Vol. 3, $1520-1524$.

Sheela KG, Deepa SN. Review on Methods to Fix Number of Hidden Neurons in Neural Networks. Mathematical Problems in Engineering (2013), 11 pages, http://dx.doi.org/10.1155/2013/425740/

Sheremet A, Mehta AJ, Liu B. Stone G.W. Wave-sediment interaction on a muddy inner shelf during Hurricane Claudette. Estuar Coast Shelf S (2005) 63, 225-233.

Son M, Hsu T. Flocculation model of cohesive sediment using variable fractal dimension. Environmental Fluid Mechanics (2008); 8 (1): 55-71.

Soulsby R. Dynamics of marine sands, a manual for practical applications. Thomas Telford, Wallingford, England (1997).

Soulsby RL, Manning AJ, Spearman J, Whitehouse RJS. Settling velocity and mass settling flux of flocculated estuarine sediments. Marine Geology (2013); 339, 1-12, http://dx.doi.org/10.1016/j.margeo.2013.04.006.

Stokes GG. On the effect of the internal friction of fluids on the motion of pendulums: Cambridge Philosophical Society, Transactions (1851); v. 9, no. 8, p. 287.

Thorne PD, Hanes DM. A review of acoustic measurement of small-scale sediment processes. Cont Shelf Res (2002); 22(4):603-632.

Thorne PD, MacDonald IT, Vincent CE. Modelling acoustic scattering by suspended flocculating sediments. Cont Shelf Res (2014); 88: 81-91. 
Toorman EA, Bruens AW, Kranenburg C, Winterwerp JC. Interaction of suspended cohesive sediment and turbulence. in: Proceedings in Marine Science, 5: Fine sediment dynamics in the marine environment (J.C. Winterwerp and C. Kranenburg eds.) (2002); pp. 7-23, Elsevier Science, Amsterdam.

Tsai CH, Iacobellis S, Lick W. Flocculation of fine-grained lake sediments due to a uniform shear stress. Journal of Great Lakes Research (1987); 13: 135-146. doi:10.1016/S0380- 1330(87)71637-2.

Uncles RJ, Bale AJ, Stephens JA, Frickers PE, Harris C. Observations of floc sizes in a muddy estuary. Estuarine, Coastal and Shelf Science (2010); 87, 186-196.

Verney R, Lafite R, Brun-Cottan J. Behaviour of a floc population during a tidal cycle: laboratory experiments and numerical modelling. Cont Shelf Res (2011); 31: S64-S83.

Winterwerp JC. A simple model for turbulence induced flocculation of cohesive sediment. J Hydraul Res (1998); 36 (3): 309-326.

Winterwerp JC. On the dynamics of high concentration mud suspensions. PhD thesis, Tech. Univ. of Delft, The Netherlands (1999).

Winterwerp JC, van Kesteren WGM. Introduction to the physics of cohesive sediments in the marine environment. Elsevier, Developments in Sedimentology, 56 (2004).

Winterwerp JC, Manning AJ, Martens C, de Mulder T, Vanlede J. A heuristic formula for turbulence-induced flocculation of cohesive sediment. Estuarine, Coastal \& Shelf Sci. (2006); 68, 195-207. 


\begin{tabular}{rrc}
\hline & Parameters & Range involved \\
\hline \hline Input & $\mathrm{SSC}\left(\mathrm{kg} / \mathrm{m}^{3}\right)$ & $0.20-2.07$ \\
\hline & Shear rate $\left(\mathrm{s}^{-1}\right)$ & $0.11-3.63$ \\
\hline & Salinity $(\mathrm{psu})$ & $24.95-29.54$ \\
\hline Output & Temperature $\left({ }^{o} \mathrm{C}\right)$ & $18.21-21.08$ \\
\hline
\end{tabular}

Table 1: Range of input and output parameters.
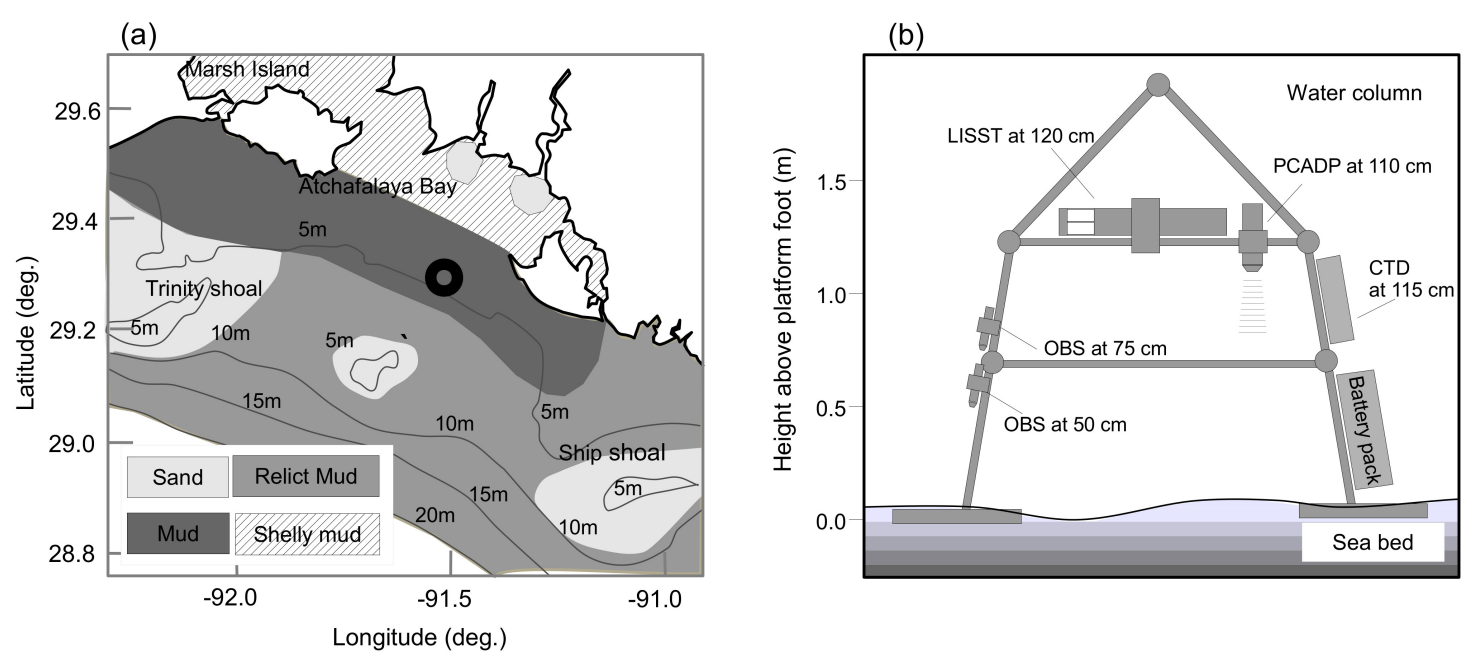

Figure 1: (a) Approximate distribution of the surficial sediments on the Atchafalaya Shelf. The circle marks the location of the instrumented platform (29.26 degrees latitude North, 91.57 degrees longitude West). (b) Diagram of the mooring with arrangement of the instruments. 


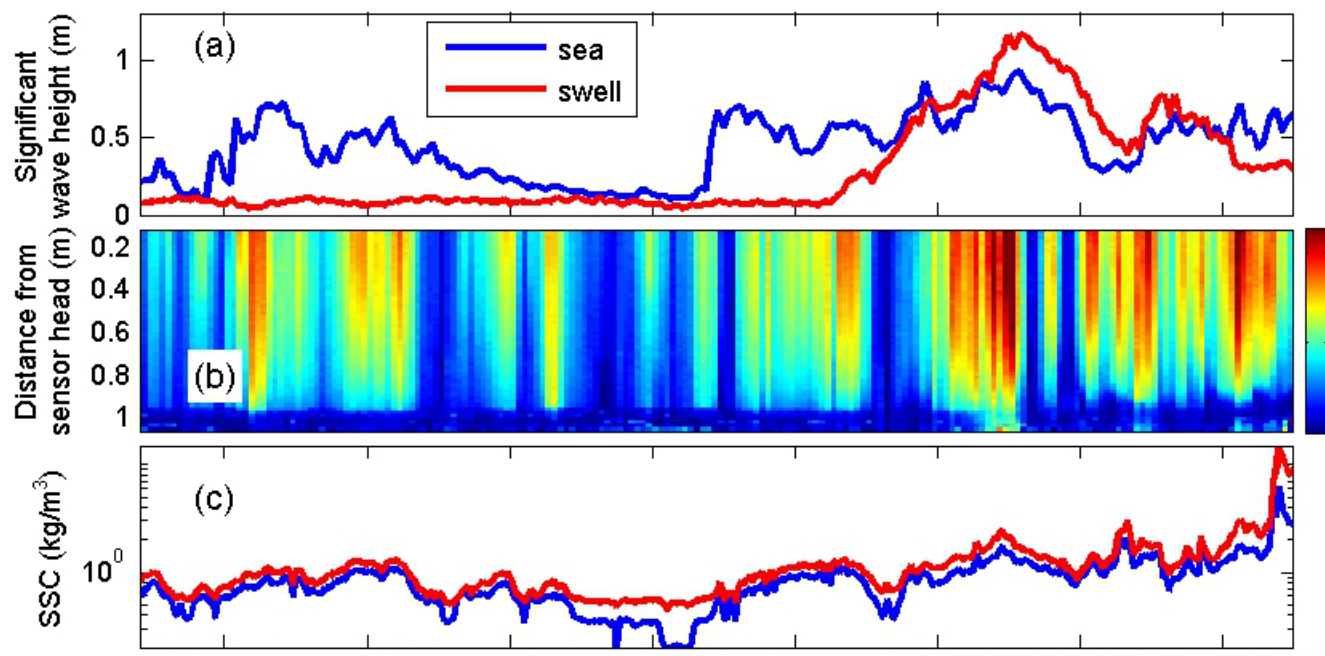

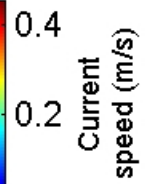
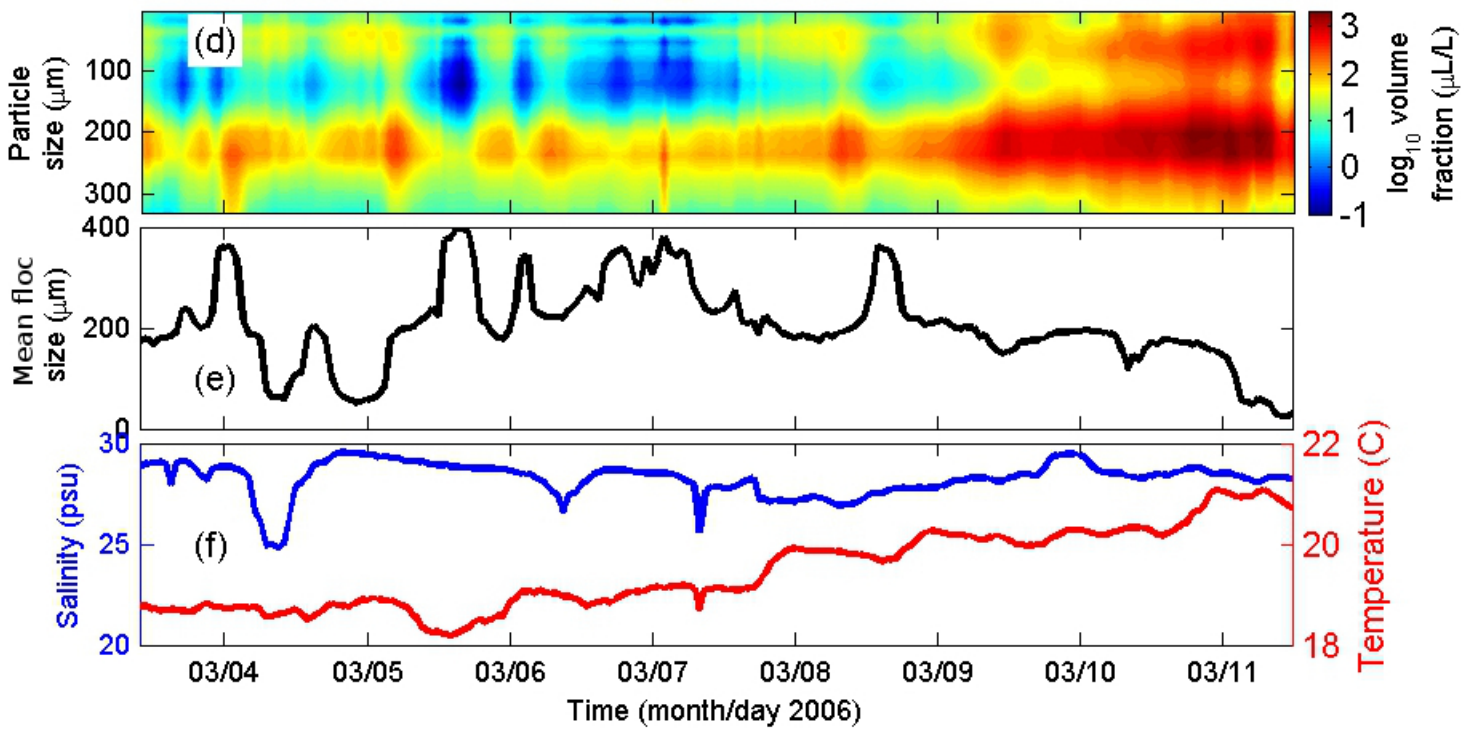

Figure 2: Time evolution of (a) significant wave height at the surface in the sea ( $f>0.2 \mathrm{~Hz}$, thin line) and swell ( $f \leq 0.2 \mathrm{~Hz}$, thick line) bands; (b) the PC-ADP measurements of current speed profiles; (c) suspended sediment concentration measured by the OBS-3s (red: $50 \mathrm{cmab}$, blue: $75 \mathrm{cmab}$ ); (d) fractional volume of each particle size, calculated from hourly averaged LISST data; (e) mean floc size extracted from LISST data; (f) salinity (blue) and temperature (red) measurements. 

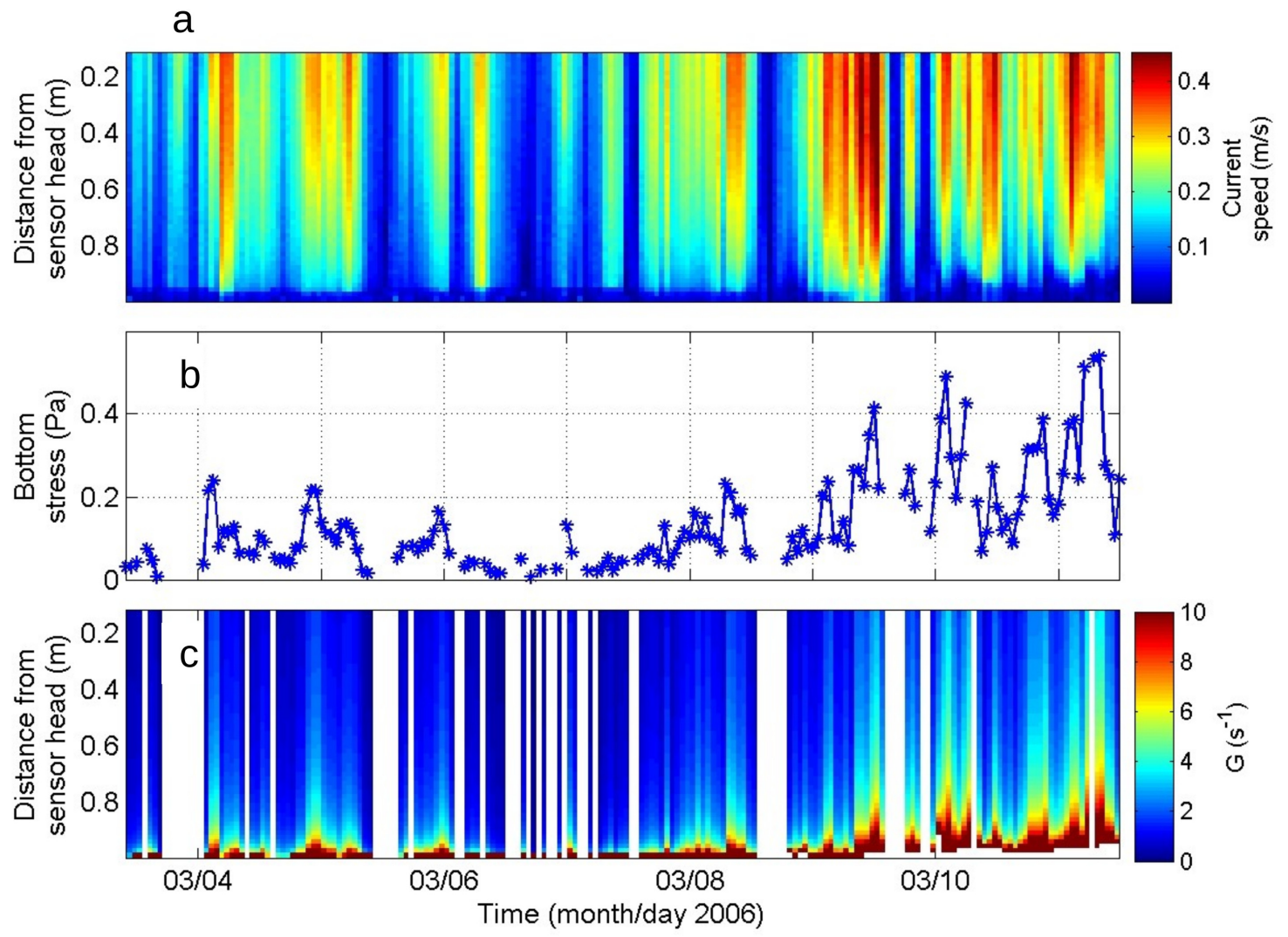

Figure 3: Time evolution of (a) current speed profiles; (b) bottom shear stress estimates based on the loglaw; (c) vertical profiles of the velocity shear estimates. Data gaps correspond to the bursts having non-valid logarithmic current profiles. 


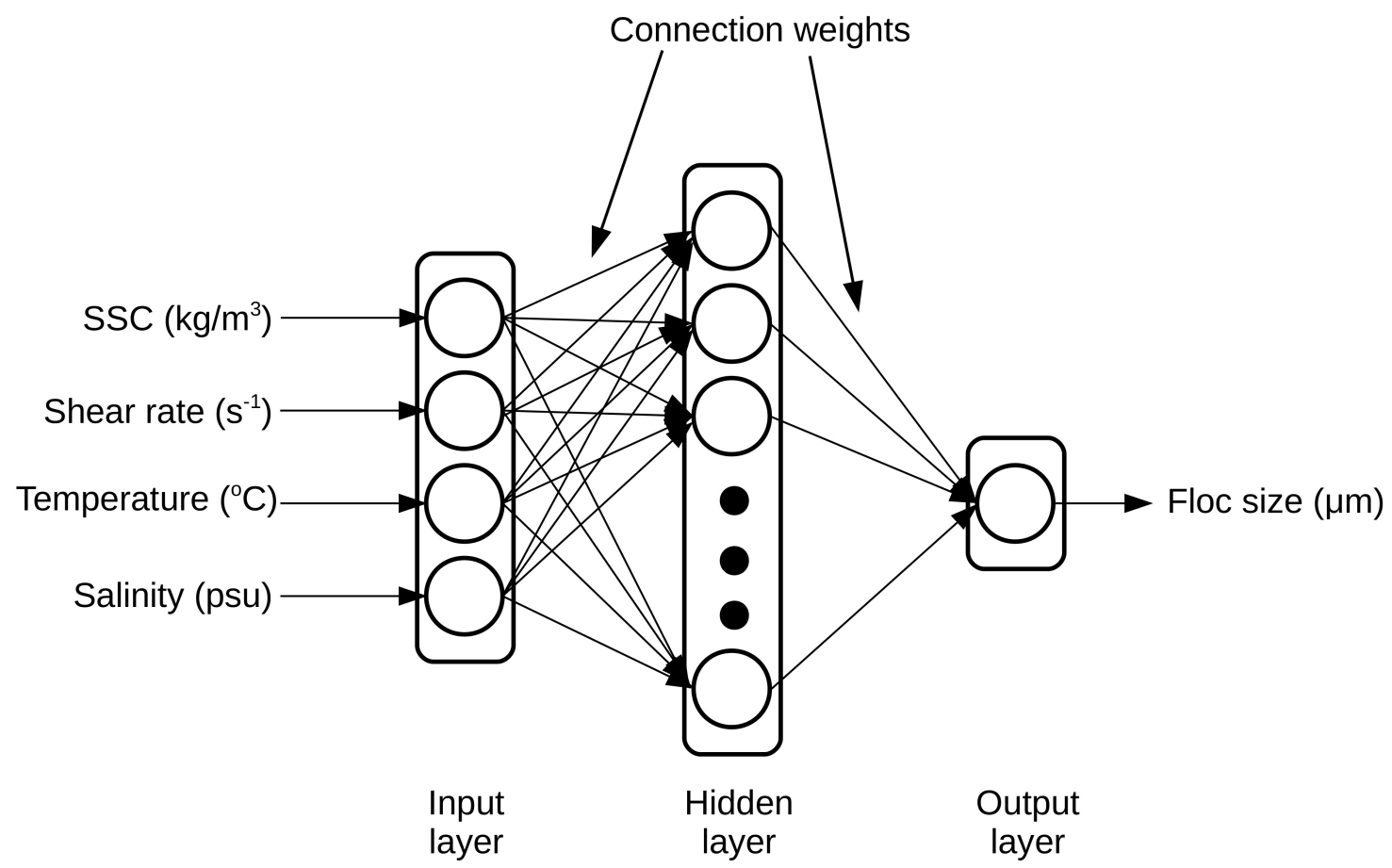

Figure 4: The network architecture of the ANN model for prediction of mean floc size. 

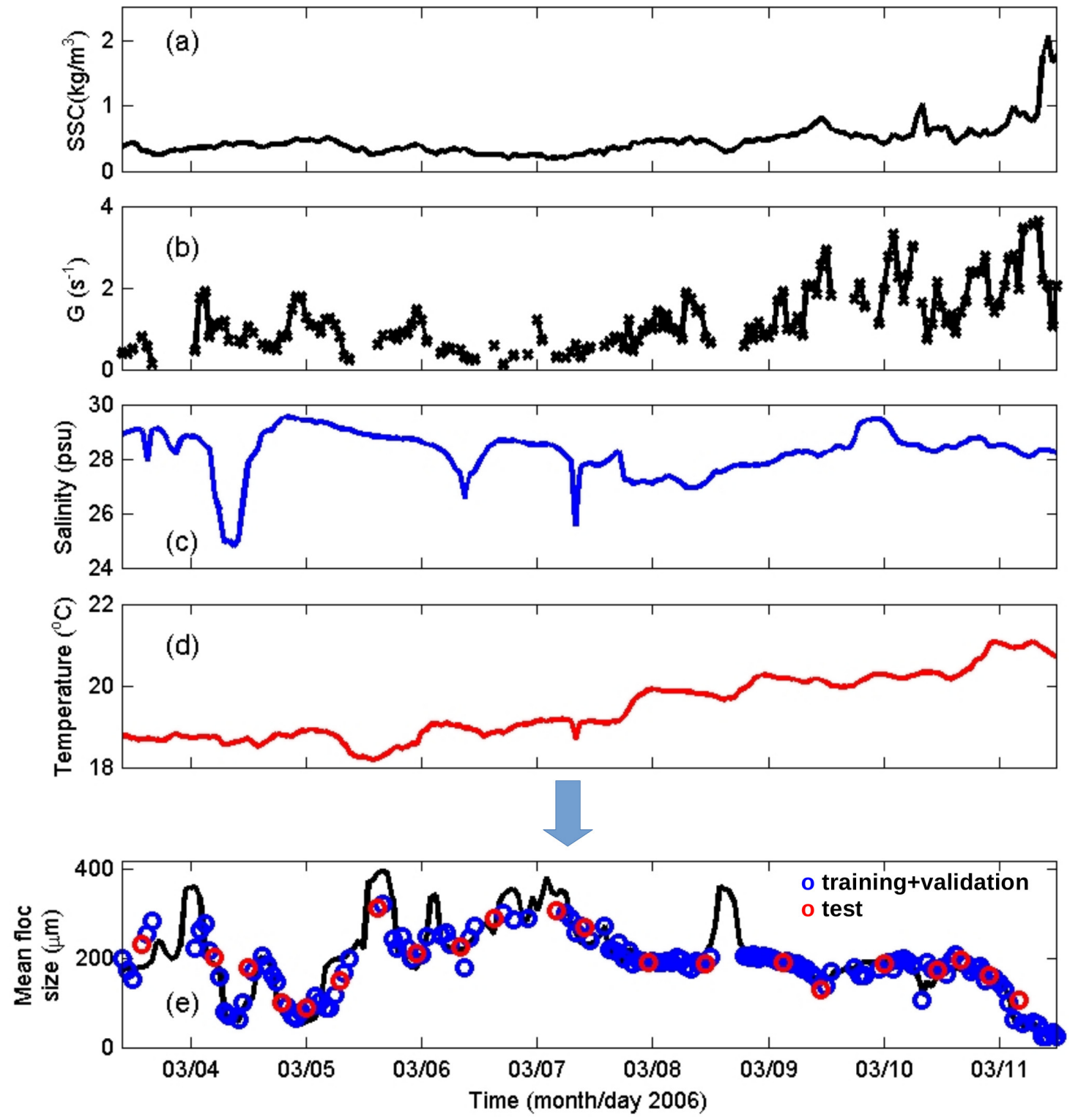

Figure 5: Data used for development of the ANN model. Time evolution of (a) suspended sediment concentration at approximately $1 \mathrm{mab}$, (b) shear rate at approximately $1 \mathrm{mab}$, (c) salinity at $1.1 \mathrm{mab}$, (d) temperature at $1.1 \mathrm{mab}$ and (e) mean floc size at $1.2 \mathrm{mab}$. Solid line in panel (e) indicates the measured floc sizes. Blue and red circles in panel (e) indicate the model estimates for training-validation and test data, respectively. 

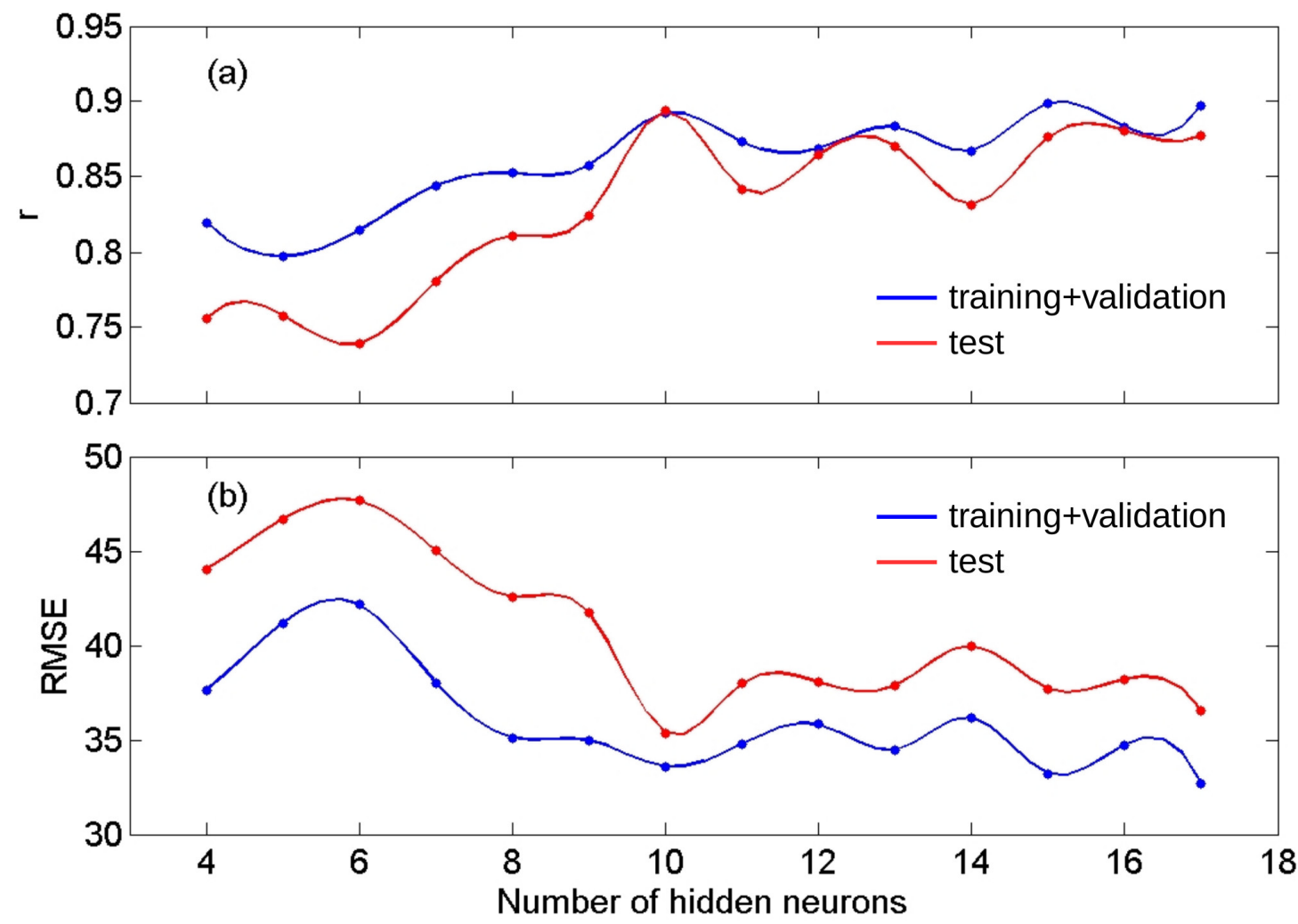

Figure 6: Variations of (a) correlation coefficient and (b) root-mean-square error with the number of hidden neurons for calibration. Blue and red curves indicate the values for training-validation and test data, respectively. 


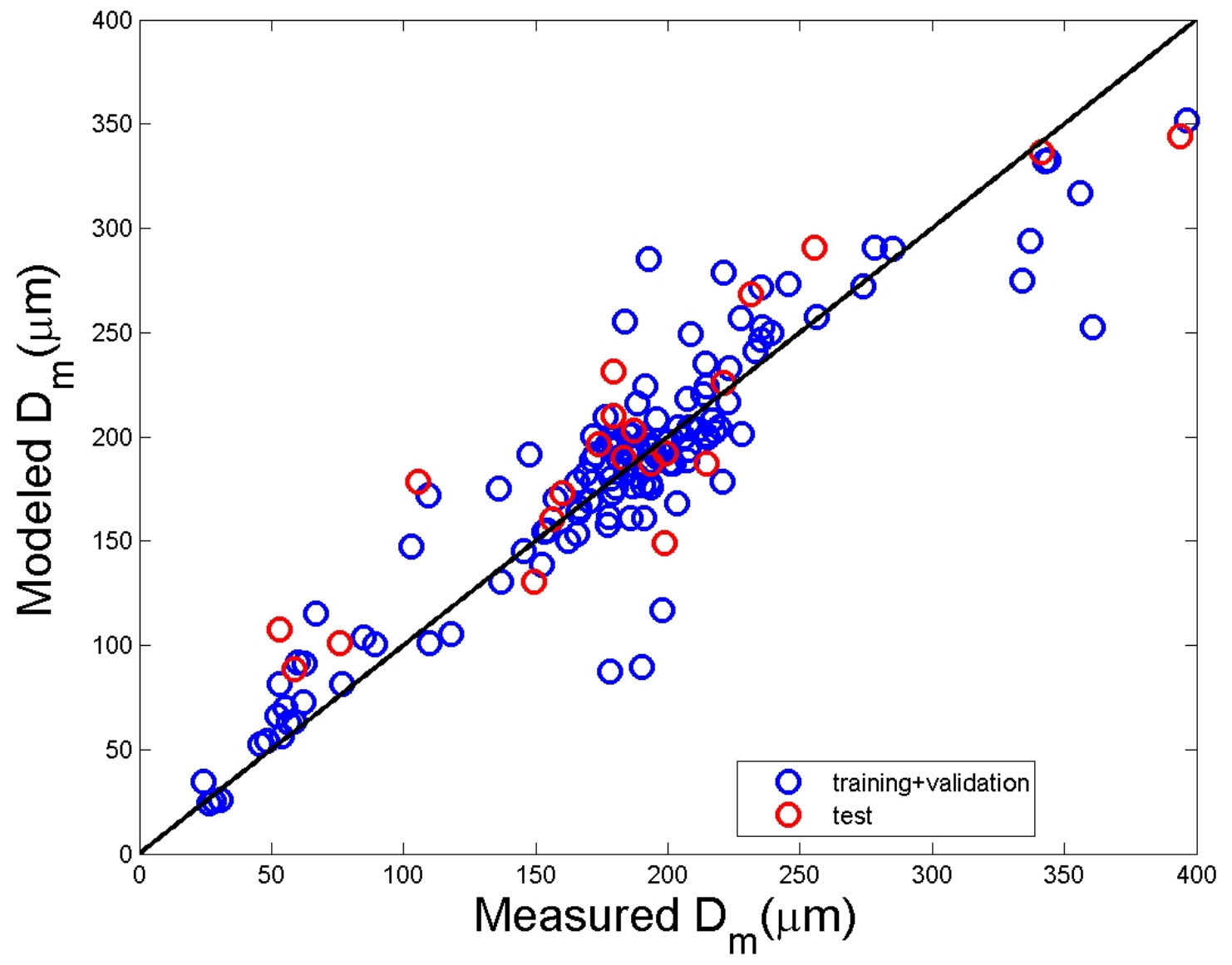

Figure 7: Correlation between measured and modeled mean floc sizes for training-validation data (blue circles) and test data (red circles). 


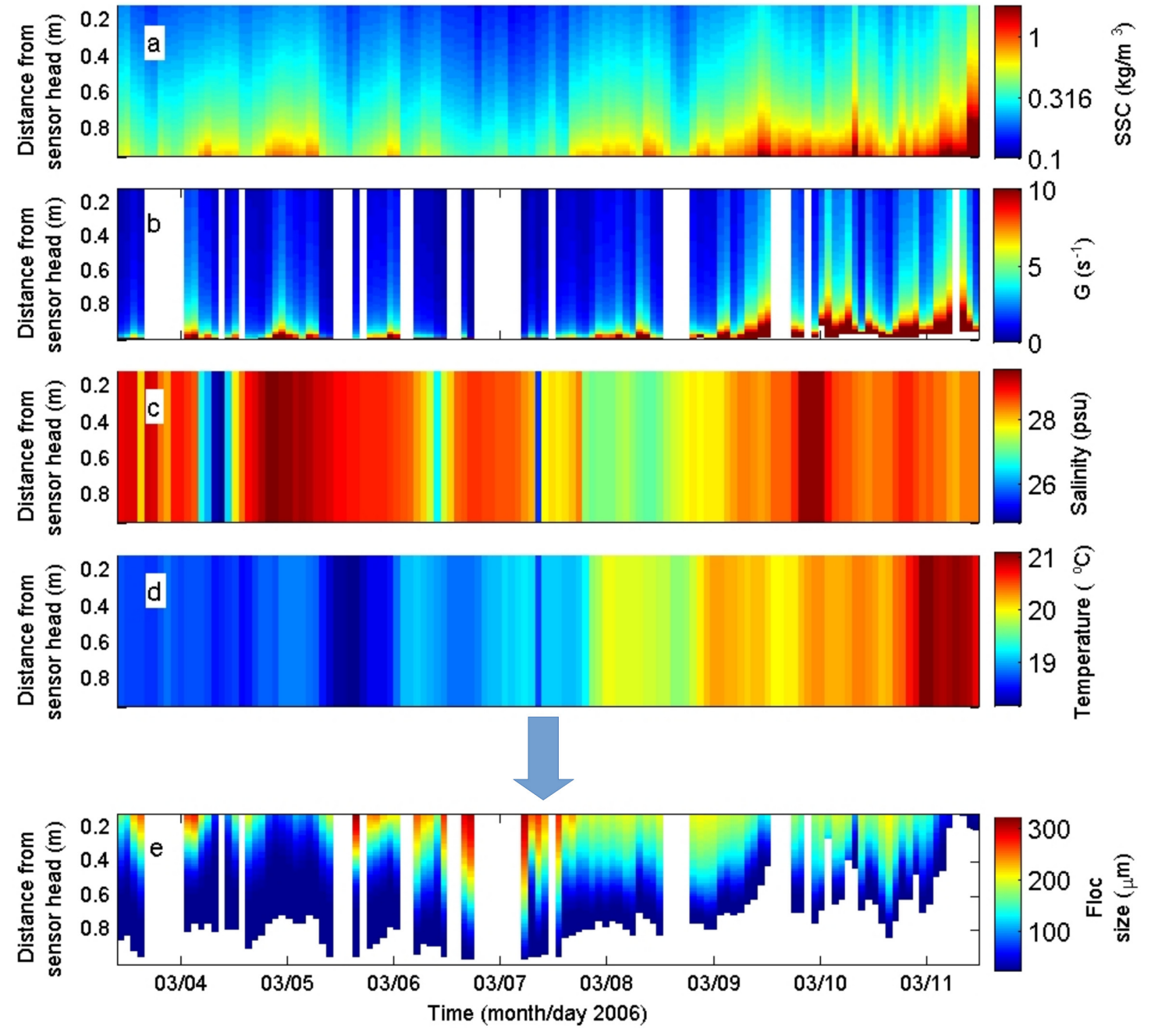

Figure 8: Model inputs (panels a-d) and output (panel e). Vertical profiles of (a) suspended sediment concentration, (b) shear rate, (c) salinity, (d) temperature and (e) modeled mean floc size. Data gaps in panel (e) correspond either to the time segments with invalid $G$ estimates (panel b) based on the log-fit velocity profiles, or to the data points in which the input data (panels a-d) are beyond the values used in model development. 


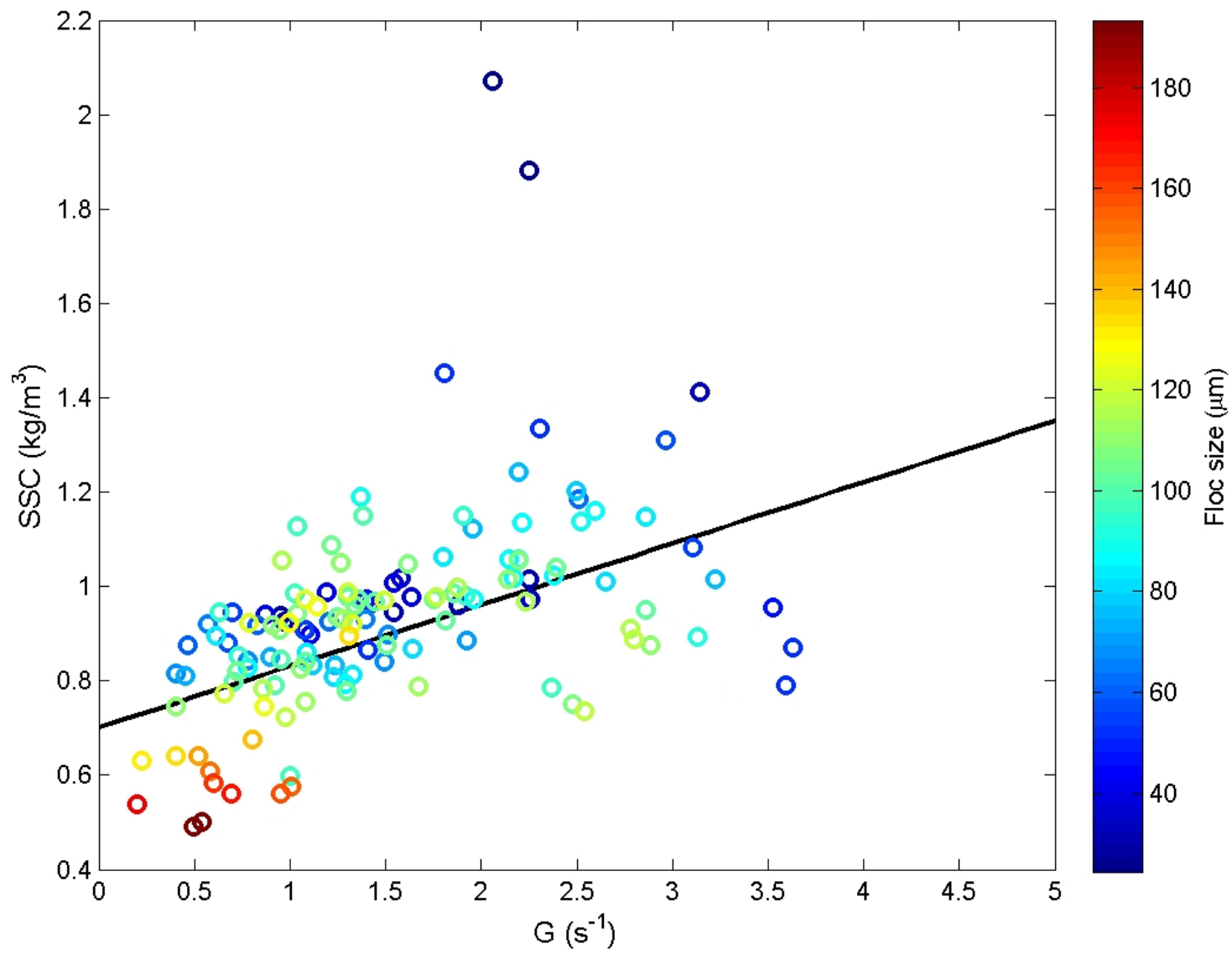

Figure 9: Variation of vertically averaged shear rate versus suspended sediment concentration. Data points indicate the vertically averaged values. Black solid line is drawn to indicate the trend $(G=0.13 \times \mathrm{SSC}+0.7$, where $G$ is in $\mathrm{s}^{-1}$ and $\mathrm{SSC}$ is in $\mathrm{kg} / \mathrm{m}^{3}$ ). Color bar indicates corresponding mean floc size values. 

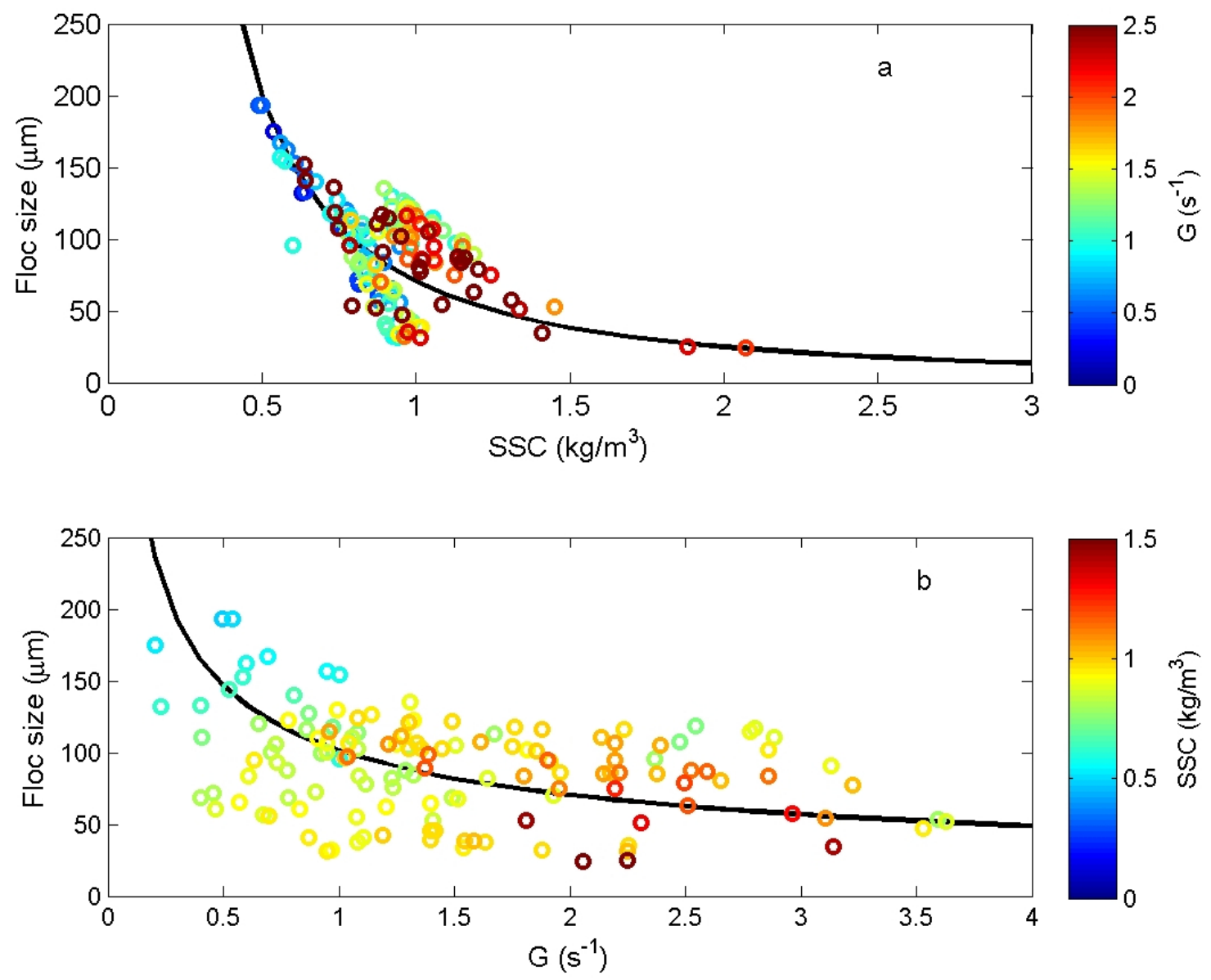

Figure 10: Variation of (a) suspended sediment concentration versus mean floc size, (b) shear rate versus mean floc size. Data points indicate the vertically averaged values. Black solid lines are drawn to indicate the trends $\left(D_{m}=70.3 \times \mathrm{SSC}^{-1.5}\right.$ and $D_{m}=101.6 \times G^{-0.53}$, where $D_{m}$ is $\mu \mathrm{m}, \mathrm{SSC}$ is in $\mathrm{kg} / \mathrm{m}^{3}$ and $G$ is in s$\left.{ }^{-1}\right)$. Color bars in panels (a) and (b) indicate corresponding shear rate and concentration values, respectively. 

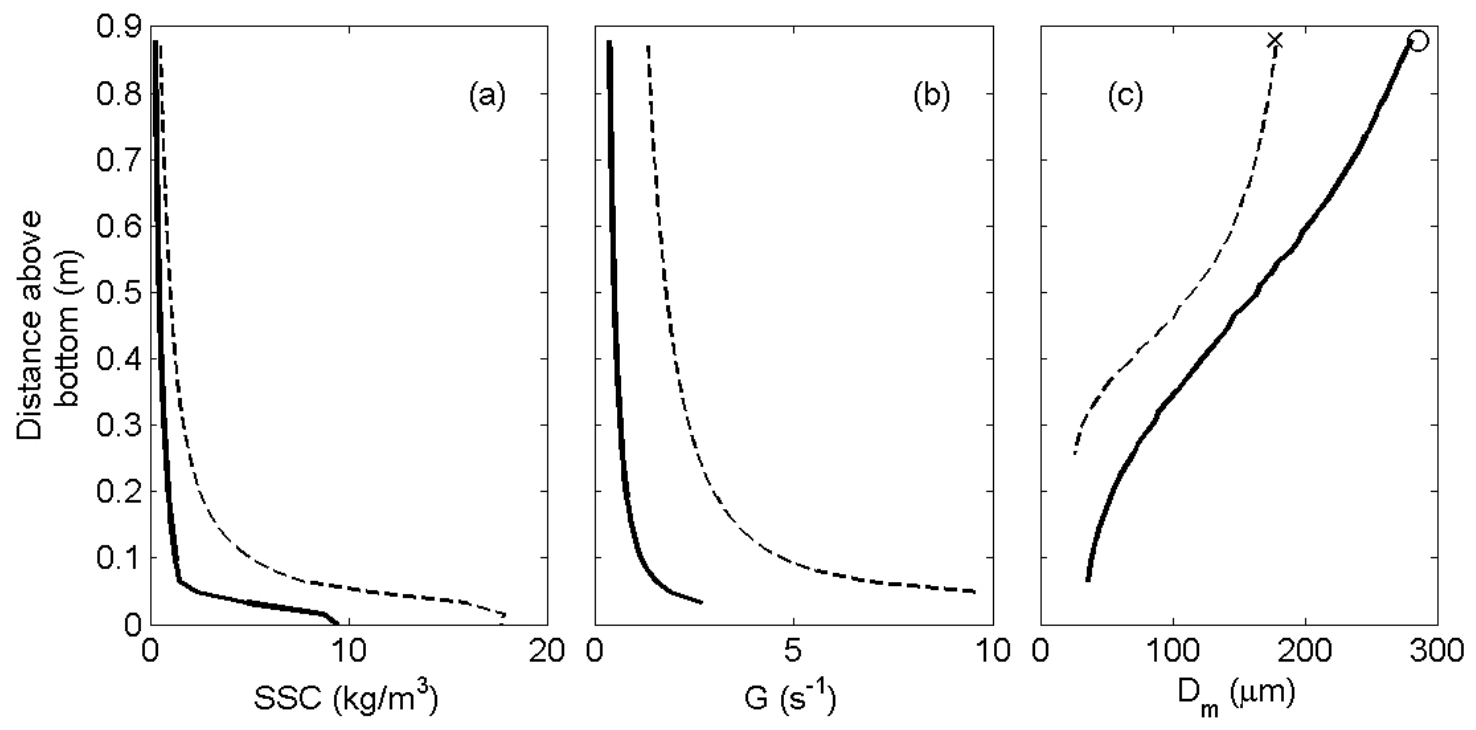

Figure 11: (a) Two observed SSC vertical profiles representing high-energy (represented by strong wavecurrent activity, dashed line: March, 10th at 14:00 h UTC) and low-energy conditions (represented by weak wave-current activity, continuous line:March, 6th at 22:00 h UTC). (b) Corresponding vertical shear rate profiles. (c) Corresponding modeled vertical mean floc size profiles. 